\title{
ACTIVE VERSUS PASSIVE POLICIES OF UNEMPLOYMENT: GROWTH AND PUBLIC FINANCE PERSPECTIVES \\ Rangan Gupta ${ }^{1}$ and Charlotte B du Toit \\ Department of Economics, University of Pretoria
}

\begin{abstract}
This paper develops a general equilibrium endogenous growth model in an overlapping generations framework, and compares, in terms of economic growth, a passive unemployment policy (unemployment insurance) with an active unemployment policy (government expenditures targeted towards improving the job-finding probability of an unemployed). Besides, the standard result of unemployment being growth reducing, under realistic parameterisation, we show that the government, under an active policy, can generate higher growth without any compromise on its own consumption, when compared to the unemployment benefit regime. The result, however, depends crucially on the efficiency with which the resources are spent in creating employment.
\end{abstract}

Keywords: Active and passive policies of unemployment; unemployment benefits; endogenous growth.

JEL E24, H55, J64, O41

\section{1 \\ Introduction}

This paper develops a general equilibrium endogenous growth model in an overlapping generations framework, and compares, in terms of economic growth, unemployment insurance (a passive policy of unemployment) with a policy in which government expenditures are intended to improve the likelihood of an unemployed person finding employment (active policy of unemployment). Government policy involves training or educating the unemployed to develop the skills necessary for them to be absorbed into the labour force, or removing the rigidities in the labour market or reducing search costs, or all of the above. So the active unemployment policy, unlike the unemployment insurance policy, targets unemployment directly, and, in turn, seeks to absorb the unemployed into the workforce.

Surprisingly, despite the fact that the relationship between social security, unemployment and growth is important to the layman and policy-makers alike, the topic has been largely ignored in the theoretical literature. However, two recent studies by Saint-Paul (1992) and Belan et al (1998), which theoretically analyse the roles of pension funds and growth, have attracted interest from growth theorists. Moreover, recent papers by Aghion and Howitt (1994), Bräuninger (2000), Pissarides (2000) and Lingens (2003) study the effect of unemployment on economic growth. While Aghion and Howitt (1994) and Pissarides (2000) consider unemployment caused by search frictions, Bräuninger (2000) and Lingens (2003) examine unemployment caused by wage bargaining. However, all these studies reach the identical conclusion that unemployment impedes growth. However, Daveri and Tabellini (2000) argue that slowdown in economic growth causes a rise in unemployment, which, in turn, is caused by the increase in tax on labour income. As labour income taxes include social security contributions, there understandably exists an indirect link between pension funds and unemployment and growth. Most importantly, 
however, their conclusions explain the upward trend in European unemployment between 1965 and 1995, when the labour tax rates increased by 14 percentage points.

The only two papers that explicitly consider the relation between social security, unemployment and growth are those of Corneo and Marquardt (2000) and Bräuninger (2005). Although the models are very similar in spirit, their conclusions differ markedly. While Bräuninger (2005) indicates that unemployment has a negative impact on growth, Corneo and Marquardt (2000) show that, in fact, it does not affect growth. Moreover, while the study by Corneo and Marquardt (2000) concludes that an increase in unemployment benefits does not affect unemployment, Bräuninger (2005) shows that unemployment increases with the rise in the unemployment benefits. Our model, however, does not attempt to link unemployment insurance with growth. On the contrary, it shows that, if government expenditures were to be targeted at generating employment (through training or by reducing labour market rigidities that prevent firms from hiring or by reducing search costs) rather than providing unemployment insurance, the government could not only generate a higher level of economic growth, compared to the unemployment insurance policy in place, but could achieve this without compromising its own consumption. But this would only happen if the government were to achieve a critical level of efficiency in carrying out such expenditures. However, it must be noted that nothing precludes our model from analysing the impact of a change in unemployment and unemployment insurance on economic growth. To the best of our knowledge, this is the first attempt at comparing the policy of unemployment insurance with an active governmental policy aimed at reducing the likelihood of people remaining unemployed in terms of growth and from the perspective of public finance. Thus far, then, the general equilibrium model of unemployment has focused mainly on the link between labour market policies, wage formulation and the level of unemployment. ${ }^{2}$.

The remainder of the paper, besides the introduction and conclusions, is organised as follows: Section 2 sets out the economic environment under the passive and active policies of unemployment respectively. Section 3 sets out the equilibrium, while Section 4 solves and compares the model in terms of growth, according to the two alternative policies.

\section{2}

\section{Economic environment}

This section presents a modified version of Diamond's (1965) overlapping generations model, by accounting for unemployment. The economy is populated by three types of agents: consumers, who can be employed or unemployed, firms and an infinitely-lived government. The following subsections set out the economic environment in detail, by considering each of the agents separately and accounting for the two alternative economic policies discussed above.

\subsection{Passive policy of unemployment: unemployment benefits}

\subsubsection{Consumers}

The economy is characterised by an infinite sequence of two period-lived overlapping generations of economic agents. Time is discrete and is indexed by $t=1,2, \ldots$. At each date $t$, there are two coexisting generations of young and old agents. At $t=1$, there exist $N$ people in the economy called the initial old, who live for only one period. Hereafter $N$ is normalised to 1.

Each consumer is given one unit of working time $\left(n_{t}\right)$ when young. However, a fraction $(u)$ of the population is unemployed; hence there are $(1-u)$ working individuals in the economy. The employed agents are assumed to retire when they are old. The employed agent supplies the one unit of labour inelastically and receives a competitively determined real wage of $w_{t}$. If employed, the consumer has to pay a tax at the rate of $\tau_{t}$. The unemployed consumer, on the other hand, receives an unemployment benefit to the order of $\theta_{t} w_{t}$, with $0<\theta<1$, where $\theta$ is the replacement ratio. We assume that the agents consume only when old. ${ }^{3}$ The net of tax wage earnings of the employed and the 
unemployment benefit of the unemployed obtained when young is thus allocated entirely to savings in the form of investment in the firms of the economy. The proceeds from the savings are then used to obtain second period consumption by both the employed and the unemployed, individually.

With $\left(1+r_{t+1}\right)$ as the gross real rate of interest, the problems of the employed $(e)$ and the unemployed $(u)$ respectively can be formally described as follows:

$$
\max U\left(c_{t+1}^{e}\right)
$$

s. to.

$$
\begin{aligned}
& s_{t}^{e} \leq\left(1-\tau_{t}\right) w_{t} \\
& c_{t+1}^{e} \leq\left(1+r_{t+1}\right) s_{t}^{e} \\
& \max U\left(c_{t+1}^{u}\right)
\end{aligned}
$$

s. to.

$$
\begin{aligned}
& s_{t}^{u} \leq \theta_{t} w_{t} \\
& c_{t+1}^{u} \leq\left(1+r_{t+1}\right) s_{t}^{u}
\end{aligned}
$$

As the agents consume only when old, the specification of the utility function does not matter, because the problem is solved directly from the constraints. However, the usual assumptions of positive but diminishing marginal utility, along with the INADA conditions, still hold.

\subsubsection{Firms}

All firms are identical, and produce a single final good using a constant return to scale, Cobb-Douglas-type, production function, given as follows:

$y_{t}=A k_{t}^{\alpha}\left(L_{t} \overline{k_{t}}\right)^{1-\alpha}$

where $y_{t}$ is the output; $L_{t}$ is the inelastic labour supply by the employed, for production in period $t ; k_{t}$ is the per-firm capital stock in period $t ; \bar{k}_{t}$ denotes the aggregate capital stock in period $t ; A$ is a positive scalar, and; $0<\alpha<1$ is the elasticity of output with respect to capital. According to Romer (1986), the aggregate capital stock enters the production function in (7) to account for a positive externality indicating an increase in labour productivity as society accumulates capital stock. It must be noted that in equilibrium, $k_{t}=\bar{k}_{t}$.
At time $t$, the final good can be either consumed or stored. Firms operate in a competitive environment and maximise profit, taking the wage rate and the rental rate on capital as given, besides, $\bar{k}_{t}$. The producers convert the available household savings into fixed capital formation. It should be noticed that the production transformation schedule is linear, so that the same technology applies to both capital formation and the production of consumption goods. The authors concur with Diamond and Yellin (1990) and Chen et al (2000) in assuming that the goods producer is a residual claimer, i.e. the producer ingests the unsold consumption good in a way consistent with lifetime maximisation of the value of the firms. This ownership assumption avoids unnecessary Arrow-Debreu redistribution from firms to households and simultaneously maintains the general equilibrium nature.

The representative firm at any point of time $t$ maximises the discounted stream of profit flows subject to the capital evolution constraint $\left(k_{t+1} \leq\left(1-\delta_{k}\right) k_{t}+i_{k t}\right)$. Given that $w_{t}$ and $1+r_{t+1}$ is the real wage rate and the gross rate of return on capital respectively, and defining $\delta_{k}$ as the constant rate of depreciation of physical capital, we have, following profit maximisation, for all periods ${ }^{4}$ :

$w_{t}=A(1-\alpha) k_{t}\left(L_{t}\right)^{(-\alpha)}$

$$
\left(1+r_{t+1}\right)=\frac{\rho A \alpha\left(L_{t}\right)^{(1-\alpha)}}{1-\rho\left(1-\delta_{k}\right)}
$$

With $\rho$ as the firm owner's discount factor, equation (9) provides the condition for the optimal investment decision of the firm. The firm compares the cost of increasing investment in the current period with the future stream of benefit generated from the extra capital invested in the current period, i.e. (9) equates the marginal benefit of capital with its marginal cost. Equation (8), on the other hand, simply states that the firm hires labour up to the point where the marginal product of labour equates the real wage. So conditions (8) and (9) imply that profit maximisation of the firms lead to a constellation in which inputs are paid their marginal products. These, in turn, exhaust the output. 


\subsubsection{Government}

In this section the authors describe the activities of an infinitely-lived government. The government purchases $g_{t}$ units of the consumption good and is assumed to transform these one-for-one without cost into what is called government good. A part of the government good, $g_{1 t}=\left(\theta_{t} \times\right.$ $\left.u w_{t}\right)$, is then used to provide the unemployment benefit, while the remaining amount of $g_{2 t}=$ $g_{t}-\left(\theta \times u w_{t}\right)$ is used solely for government consumption and is thus useless to the agents. The government is assumed to finance these expenditures with income taxation. Recalling that $N$ is unity, the government's budget constraint at date $t$, in per capita terms, can be formally defined as follows:

$g_{t}=\tau_{t} w_{t} \times(1-u)$

or, $g_{2 t}=\left(\tau_{t}(1-\mathrm{u})-\theta_{t} u\right) w_{t}$

\subsection{Active policy of unemployment}

The basic structure of the economy continues as above. However, with a fraction of the government expenditure now directed towards enhancing the chances of the unemployed being hired by the firm, the optimisation problem of the agents must be redefined. These government expenditures can take the form of training the unemployed, if the unemployment is in fact due to the lack of appropriate skills required for absorption into the labour force. Or, alternatively, this spending can be directed towards reducing the fixed costs incurred by the firms in labour hire or search costs for the unemployed. At this stage, the authors are not concerned with identifying reasons behind unemployment, but rather with analysing how the economy performs with an active unemployment policy.

Let $p$ be the probability of the unemployed agent in finding a job. We assign the following structure to the probability:

$p_{t}=\eta_{t}^{\gamma}$

where $\eta_{t}$ is the fraction of the aggregate wage income ${ }^{5}$ devoted to training or reducing transaction costs in the labour market for each unemployed member, and $0<\gamma<1$ captures the fact that the probability of finding a job for the unemployed agent has a decreasing rate with such expenditures. Note that probability equals unity only in the hypothetical case of the government spending the entire aggregate wage income for such purposes.

We are now ready to discuss the problems of the individual agents under the alternative policy.

\subsubsection{Households}

The optimisation problem for the employed and the unemployed, respectively, can be redefined as follows:

$$
\max U\left(c_{t+1}^{e}\right)
$$

s.t.

$$
\begin{aligned}
& s_{t}^{e} \leq\left(1-\tau_{t}\right) \overline{w_{t}} \\
& c_{t+1}^{e} \leq \overline{\left(1+r_{t+1}\right)} s_{t}^{e} \\
& \max \left[p \times U\left(c_{t+1}^{u}\right)\right]
\end{aligned}
$$

s.t.

$$
\begin{aligned}
& s_{t}^{u} \leq\left(1-\tau_{t}\right) \overline{w_{t}} \\
& c_{t+1}^{u} \leq \overline{\left(1+r_{t+1}\right)} s_{t}^{u}
\end{aligned}
$$

where $s^{i}$ and $c^{i}, i=e$ and $u$ measures the savings and consumption decision of the employed and when the unemployed find employment, respectively; $\bar{w}$ and $\overline{1+r}$ are the redefined real wage and gross real rental that the agents will receive, based on the expected labour supply.

\subsubsection{Firms}

As before, given the production function in (7), the life-time profit maximisation of the firm on imposing $k_{t}=\bar{k}_{t}$ will yield the following conditions. See the Appendix for further details:

$\overline{w_{t}}=A(1-\alpha) k_{t}\left(L_{t}\right)^{(-\alpha)}$

$\overline{\left(1+r_{t+1}\right)}=\frac{\rho A \alpha\left(L_{t}\right)^{(1-\alpha)}}{1-\rho\left(1-\delta_{k}\right)}$

It is to be noted that, given that the size of employable labour would be different under the active policy as compared to the size under the passive policy, the corresponding real wage rate and the gross real rate of return would also be different in equilibrium under the two alternative policy regimes. The returns have thus now been defined with an over-line. 


\subsubsection{Government}

As in the case of unemployment benefits, the government finances its expenditure by means of income taxes alone. Bearing in mind that the unemployed when employed with probability will have to pay tax on their earnings, the government budget constraint, under the active policy, can be written as follows:

$g_{t}=\tau_{t} \bar{w}_{t} \times(1-u)+p_{t} \tau_{t} \bar{w}_{t} \times(u)$

Equation (21) can be rewritten as follows:

$g_{2 t}=\tau_{t}[(1-u)+p \times u] \overline{w_{t}}-g_{1 t}$

where $g_{1 t}$, measures the size of government expenditure spent on enhancing the chances of the unemployed being hired by the firm, hence $g_{2 t}$ measures pure government consumption. Given that consistency with endogenous growth requires all (real) variables to grow at the same rate, we can set $g_{1 t}=\eta_{t} \times(u) \overline{w_{t}}$ without any loss of generality. This would imply, going by (22), that $g_{2 t}=\left(\tau_{t}\{\times(1-u)+p \times u\}-\eta_{t} \times u\right) \bar{w}_{t}$ and also (12), $p_{t}=\eta_{t}^{\gamma}$. We will assume that the government pursues time-invariant policy rules, which will mean that the tax rate, $\tau_{t}, \theta_{t}$ and $\eta_{t}$ and, hence, $p_{t}$ are constant over time.

\section{3}

\section{Equilibrium}

A valid perfect-foresight, competitive equilibrium for the economy with unemployment benefit [active policy of unemployment] is a sequence of allocations $\left\{c_{t+1}^{e}, c_{t+1}^{u}, n_{t}, s_{t}^{e}, s_{t}^{u}, i_{k t}\right\}_{t=0}^{\infty}$ and policy variables $\left\{\tau_{t}, g_{1 t}, \theta_{t}\left[\eta_{t}\right]\right\}_{t=0}^{\infty}$, such that ${ }^{6}$ :

- Taking $\tau_{t}, w_{t}\left[\bar{w}_{t}\right], \theta_{t}\left[\eta_{t}\right],\left(1+r_{t+1}\right)\left[\overline{\left(1+r_{t+1}\right)}\right]$, both the employed and the unemployed consumer optimally chooses $c_{t+1}^{i}$ and $s_{t}^{i}$, $i=e$ and $u$, such that (1) [13] is maximised subject to (2) and (3) [14 and 15] and (4) [16] is maximised subject to (5) and (6) [17 and 18] respectively;

- The real allocations solve the firm's date- $t$ profit maximisation problem, such that (8) and (9) [19 and 20] hold;

- All markets clear for all $t \geq 0$, with the labour market clearing on the demand side. In case of the active policy, realising that $N=1$,
$L_{t}=(1-u)$, whereas, in the case of the active policy $L_{t}=[(1-p) \times(1-u)+\mathrm{p} \times 1]$;

- $\quad$ The government budget, equation (10) [21 and 22], is balanced on a period-by-period basis.

\section{4}

\section{Comparison of growth paths under the two alternative policies}

Taking the fact that the goods market equilibrium holds, i.e., $i_{k t} \times N_{t}=\left[(1-u) s_{t}^{e}+u s_{t}^{u}\right] \times N_{t}$ (under the passive policy), $i_{k t} \times N_{t}=$ $\left[(1-u) s_{t}^{e}+u \times p \times s_{t}^{u}\right] \times N_{t}$ (under the active policy) and the capital evolution constraint implies $k_{t+1}=\left(1-\delta_{k}\right) k_{t}+i_{k t}$, we can derive the steady-state level of growth rate, under the passive and active policies of unemployment, from the combinations of equations (2), (5) and (8) and, (14), (17) and (19), respectively. Formally, the derived equilibrium growth-paths can be outlined as follows:

$$
\begin{aligned}
\Omega^{p p}= & {[(1-u)(1-\tau)+u \theta] \times } \\
& A(1-\alpha)(1-u)^{(-\alpha)}+\left(1-\delta_{k}\right) \\
\Omega^{a p}= & A(1-\alpha)[p u+(1-u)(1-\tau)] \times \\
& {[p+(1-p)(1-u)]^{-\alpha}+\left(1-\delta_{k}\right) }
\end{aligned}
$$

where, $\Omega^{i}, i=p p$ and $a p$ stands for the gross growth rate corresponding to the passive and active policies respectively.

The following observations can be made from equations (23) and (24):

(i) From (23) and (24), it is not evident whether unemployment ambiguously reduces growth. For this purpose we take the derivative of (23) with respect to $u$ to obtain:

$$
-\frac{A(1-\alpha)}{(1-u)^{(1+\alpha)}}[(1-u(1-\alpha))(1-(\tau+\theta))
$$

$-\alpha(1-\tau)]$. For realistic values of $\tau(=0.25)$,

$\theta(=0.10), \alpha(=0.4)$, the value of the above derivative is negative, unless for an impractical unemployment rate of 89.74 per cent. In the case of the active policy, the derivative of (24) with respect to $u$ yields: $-(1-p)(1-(1-p) u)^{-\alpha}(1-\tau)[1-\alpha]$, which is always negative;

(ii) An increase in the unemployment benefit brought about by a reduction in unproductive 
public expenditures, $g_{2 t}$, and not financed by means of an increase in tax rate, unambiguously increases the rate of growth. However, an increase in the unemployment benefit financed through an increase in the tax rate will reduce the rate of growth;

(iii) For the above set of parameter values, along with $\delta_{k}=0.05$ and an unemployment rate $(u)$ of $\frac{1}{3}$, the value of $A$, required to produce a growth rate of 2.5 per cent, chosen to match world figures ${ }^{7}$, under the passive policy, is equal to 0.1993 . For the same set of parameters, the probability of finding employment for the unemployed that ensures that the growth rate under the active policy is also equal to 2.5 per cent, can be obtained by setting equations (23) and (24) to be equal and solving for $p$. Mathematically, the following equation holds:

$$
\frac{0.75\left(\frac{2}{3}+\frac{p}{3}\right)}{\left(1+\frac{-1+p}{3}\right)^{0.4}}-0.627242=0
$$

(iv) The above equation can only be solved non-algebraically. So to obtain the value of $p$, we plot the left-hand side of equation (25) as a function of $p$, denoted by $f$, as shown in Figure 1, and measure where the function intersects the $X$-axis, or where the function reaches zero for a value of $p$. A grid search around this point reveals $p$ to be equal to 0.227125 . Hence, a probability of approximately 23 per cent under our chosen set of parameter values could ensure a growth rate of 2.5 per cent under the active policy;

Figure 1

Calculation of probability under the active policy

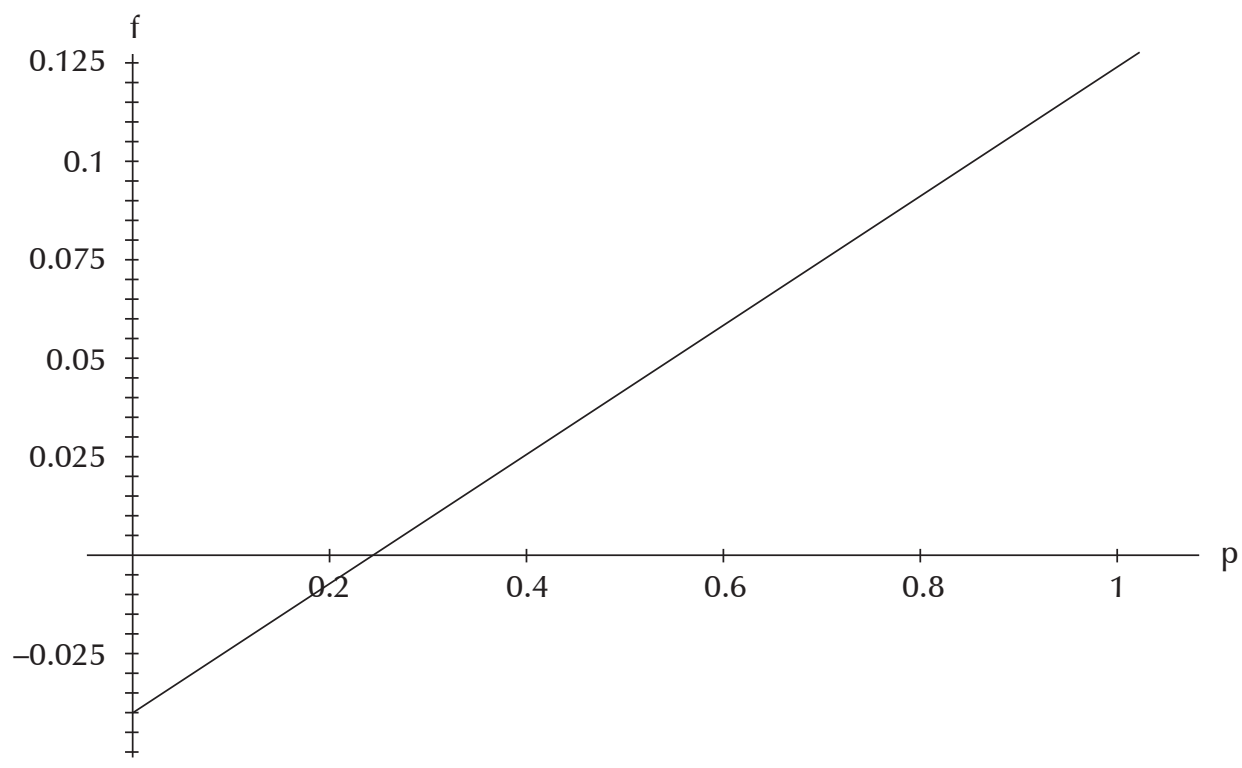

(v) More importantly, from a public finance perspective, if the value of $y=\frac{1}{2}, \eta$ were equal to $(0.227125)^{2}$ or 0.0515858 , as $p=\eta^{\gamma}$, it would mean that it would be possible for the government to generate the same growth rate by spending a lesser fraction of the wage income, as compared with the 10 per cent spent under the passive policy. It is easy to show that, unless $y \geq 0.643735$, under the given set of parameterisation, the government will always spend less than 10 per cent of the wage income for generating a growth rate of 2.5 per cent under the active policy;

(vi) However, it is also important to deduce the fraction of the wage income available purely for government consumption. In the case of passive policy, this is 6.67 per cent ${ }^{8}$ of the 
wage income, while, in the case of the active policy, it is 13.40 per cent of wage income. ${ }^{9}$ Under the active policy, the government not only spends fewer resources to generate the same level of growth rate as with the passive policy, but more importantly, does so by consuming a greater fraction of the resources available, based on the same tax rate. Given a value of $p=0.227125$, therefore, the government will continue to consume a greater fraction of the wage income under the active policy, unless the value of $y$ increases, or alternatively, the efficiency measure of the government declines to 0.696141 ;

(vii)Further, taking the derivative of $\Omega^{a p}$ with respect to $p$ yields the following result:

$$
\frac{A u(-1+\alpha)^{2}(1-r)}{(1-(1-p) u)^{\alpha}} \text {, }
$$

which is always positive. Then, understandably, an increase in the probability of the unemployed of finding employment increases the growth rate of the economy. This increase in probability can occur on account of either an increase in $\eta$, i.e., the government spends more resources for generating employment for the employed, or a fall in $y$, i.e., the government becomes more efficient. However, if the increase in $\eta$ is financed by means of an increase in tax rate, the growth rate will fall;

(viii) Suppose the value of $\eta=0.1$ were to be reset, but retaining $y=\frac{1}{2}$, then $p$ is equal to 0.316228 . Replacing this value of $p$ in equation (24), but retaining all the other parameter values under the passive policy yields a growth rate of 2.68 per cent, which is higher than the 2.5 per cent. Going by the government budget constraint, this further implies that the fraction of resources now available for government consumption is 0.093019 , which is still greater than the fraction of resources $(0.0666667)$ available to the government for consumption under the passive policy. As long as the value of $y$ is less than equal to 0.556534 , the government will continue to consume more resources under the active policy, as compared with consumption under the passive policy, given that $\eta=0.1$ and $p=0.316228$. However, the fraction of resources currently consumed by the government, which is 9.30 per cent, is less than the 13.40 per cent consumed under the original scenario, when the government spent 5.17 per cent of the wage income to generate a growth rate of 2.5 per cent;

(ix) Alternatively, consider the supposition that the government became efficient in allocating resources to generate employment opportunities for the unemployed. If $y=\frac{1}{4}$, then with $\eta$ retained at 0.0515858 , the value of $p$ increases to 0.476576 , which translates into a growth rate of 2.993 per cent and a value of 0.154796 for government consumption as a fraction of wage income. Both these values are clearly higher than the corresponding values under the passive policy, as well as under the active policy, with an initial value of $p=0.227125$. Further, if $y$ $=\frac{1}{4}$, the value of $\eta$ required to generate a $p$ of 0.227125 , is 0.00266 , which is less than the value of $\eta(0.0515858)$, with $y=\frac{1}{2}$. In this situation, although there would still be a growth rate of 2.5 per cent, the fraction of wage income consumed by the government would be equal to 0.182933 , which is clearly higher than the corresponding values under the passive and active policies, with a value of $\eta=0.0515858$ and $y=\frac{1}{2}$.

In summary, it is observed that the active policy could yield a higher growth rate, and also have the government consume a greater fraction of the wage income in comparison with the passive policy, but this would require the government to reach a certain level of efficiency in allocating resources for generating employment for the unemployed, or, alternatively, achieving a threshold level of efficiency in implementation and translation of the active policies into reality. ${ }^{10}$ Intuitively speaking, the difference between active and passive policies, in this model, essentially emanates from their effect on the private-sector budget constraint and, through that, on the process of capital accumulation. In the case of unemployment benefits, the effect is positive, when they are financed from unproductive public expenditure, because unemployment benefits in the model 
are the savings of the unemployed. In this way, unemployment benefits would put back into the capital accumulation process, that part of the resources that had been taken away by taxation. We have a similar mechanism operating for the active policy as well. This time, however, the government can choose the optimal combination of taxes and incentives to employment that maximise the aggregate growth rate, given a certain level of efficiency. The choice issue is obvious, because, with increased taxation, which, in turn, has a negative effect on growth, the government would increase the probability of employment for the unemployed, which would affect the growth rate positively. The balance between these two marginal effects would thus determine the optimal policy combination.

\section{5}

\section{Conclusions and areas for further research}

This paper develops a general equilibrium endogenous growth model in an overlapping generations framework, and compares, in terms of economic growth and a public finance perspective, a passive policy of unemployment (unemployment insurance) with an active policy of unemployment (government expenditures are targeted to enhancing the probability of the unemployed finding employment). With realistic parameterisation of the model, the authors show that the government, practising the active policy, could generate higher growth as compared with that under the unemployment benefit regime. More importantly, though, the government could achieve this by not compromising on the size of its consumption. The result, however, would depend on the efficiency with which the government spent the revenue collected for generating employment for the unemployed. Other than this, our model attains the standard result of unemployment as growth-reducing. However, we show that there exists no reverse causality from growth to unemployment, as in Corneo and Marquardt (2000) and Bräuninger (2005).

Even though this study identifies the active policy as clearly superior to the passive policy in terms of generating more growth, it is silent when it comes to the structure of the labour market. This paper emphasises the lack of skill and high fixed costs of hiring as the source of unemployment. Ideally, the cause of unemployment would have to be modelled explicitly if concrete policy recommendations were to be made. That is, in order for the government to realise the problem area, there would have to be an improved model that clearly outlined the possible reasons for labour market rigidities, and consequently unemployment. This area merits further investigation. Further, it would be interesting to allow for productive public expenditures, along the lines of Barro (1990), besides expenditures on unemployment benefit or enhancing the probability of the unemployed finding jobs. This, in turn, would lead to interesting trade-off issues, where the government would have to devise an optimal scheme for allocating direct (infrastructural) and indirect (unemployment-related) productive expenditures. Further, given that countries pursue (limited) unemployment insurance mechanisms alongside active labour market policies, it might be a worthwhile asking whether there was an optimal policy mix. Specifically, there could be a theoretical investigation in terms of the optimal combination of a small initial unemployment insurance system to attend to the most immediate concerns of the unemployed, along with active labour market policies designed to address the structural deficiencies over the longer term. Finally, it is crucially important for the results of our model in terms of the empirical evidence available on the performance of active policies be placed in perspective. Although the evidence on active policies tends to indicate minor effects on the probability of employment, it is important to realise that the vast majority of these studies provide evidence limited to short-run outcomes, covering, at the most, one or two years following an individual's participation in the programme. This may well be too short a period for a full assessment of the private and social returns to public investment for many of the active policy measures undertaken by the government, and surely, for the steady-state evaluations of the active policy made in this paper. Second, it is of paramount importance to ensure that the 
active measures entail: (i) in-depth counselling, job-finding incentives and job-search assistance programmes, as well as increased monitoring and enforcement of the work test; (ii) small-scale public training programmes that are well-suited to the specific needs of both job-seekers and local employers, and; (iii) early interventions, most likely at the pre-school level, to reach the disadvantaged youth. ${ }^{11}$ Even though this is not modelled explicitly, it is exactly what we had in mind when we referred to the efficiency of public investment in such active measures.

\section{Endnotes}

1 The authors would like to thank two anonymous referees for many helpful comments on an earlier version of the paper.

2 See Pissarides (2000) and Linden and Dor (2001) for further details. It must be pointed out that there exists an extensive econometric literature dealing with issues of unemployment. The empirical studies are largely based on the estimation of a matching function or a Beveridge curve, augmented with some labour market policy indicators. This approach, however, lacks proper theoretical foundations.

3 This assumption makes computations easier and also seems to be a good approximation of the reality (Hall 1988).

4 See the Appendix for the solution of the firm's optimisation problem.

5 See subsection 2.2.3 for details.

6 The terms in [] correspond to the active policy.

7 See Basu (2001) for further details.

8 Note from equation (11), we have $\frac{g_{2 t}}{w}=(\tau \times(1-\mathrm{u})-\theta)$.

9 Recall, from equation (22), $\left.\frac{g_{2 t}}{\overline{w_{t}}}={ }_{\tau}^{w_{t}}(1-u+p \times u)-\eta\right)$.

10 Note that under both policies there is no reverse causality from growth to unemployment, as in Corneo and Marquardt (2000) and Bräuninger (2005). But this is because labour market outcomes are exogenous to the growth process, and cannot be affected by it. In this current framework, only government policies can improve the chance of employment for the unemployed.

11 See Martin (1998) and references cited therein for further details.

\section{References}

AGHION, P \& HOWITT, P (1994) Growth and unemployment, Review of Economic Studies, 61: 477-494.
BELAN, P; MICHEL, P \& PESTIEAU, P (1998)

Pareto-improving social security reform with endogenous growth, The Geneva Papers on Risk and Insurance Theory, 23: 199-125.

BRÄUINGER, M (2000) Wage bargaining, unemployment and growth, Journal of Institutional and Theoretical Economics, 156: 646-660.

BRÄUINGER, M (2005) Social security, unemployment and growth, International Tax and Public Finance, 12: 423-434.

BARRO, RJ (1990) Government spending in a simple model of endogenous growth, Journal of Political Economy, 98: S103-S125.

BASU, P (2001) Reserve ratio, seigniorage and growth, Journal of Macroeconomics, 23: 397-416.

CHEN, BEEN-LON; CHIANG, YEONG-YUH

\& WANG, P (2000) Credit market imperfections, financial activity and economic growth, Vanderbilt University Working Paper, 00-W20.

CORNEO, G \& MARQUARDT, M (2000) Public pensions, unemployment insurance, and growth, Journal of Public Economics, 75: 293-311.

DAVERI, F \& TABELLINI, G (2000) Unemployment, growth and taxation in industrial countries, Economic Policy, 15: 49-104.

DIAMOND, P \& YELLIN, J (1990) Inventories and money holdings in a search economy, Econometrica, 58: 929-950.

HALL, RE (1988) Intertemporal substitution in consumption, Journal of Political Economy, 96: 339-357.

LINDEN, VAN DER B \& DOR, E (2001) Labor market policies and equilibrium unemployment: Theory and application for Belgium, Université Catholique de Louvain, Institut de Recherches Economiques et Sociales (IRES), Discussion Paper, No. 2001005.

LINGENS, J (2003) The impact of a unionized labor market in a Schumpeterain growth model, Labor Economics, 10: 91-104.

MARTIN, JP (1998) What works among labor market policies: evidence from OECD countries' experience, OECD Labour Market and Social Policy Occasional Papers, No. 35.

PISSARIDES CA (2000) Equilibrium Unemployment Theory, Cambridge: MIT Press, MA.

ROMER, P (1986) Increasing returns and long-run growth, Journal of Political Economy, 94: 1002-1037. SAINT-PAUL, G (1992) Fiscal policy in an endogenous growth model, Quarterly Journal of Economics, 107: 1243-1259. 


\section{Appendix}

The representative firm at any point of time $t$ maximises the discounted stream of profit flows subject to the capital evolution constraint. Formally, the problem of the firm can be outlined as follows:

$$
\begin{aligned}
& \max _{i_{k, L}, L_{t}} \sum_{i=0}^{\infty} \rho_{i}\left[y_{t}-w_{t} L_{t}-\left(1+r_{t+1}\right) i_{k t}\right] \\
& k_{t+1} \leq\left(1-\delta_{k}\right) k_{t}+i_{k t}
\end{aligned}
$$

The firm's problem can be written in the following recursive formulation:

$V\left(k_{t}\right)=\max _{L_{t}, k_{t+1}}\left[y_{t}-w_{t} L_{t}-\left(1+r_{t+1}\right) i_{k t}\right]+\rho V\left(i_{k t}+\left(1-\delta_{k}\right) k_{t}\right)$

The result of the above dynamic programming problem is the following first order conditions.

$i_{k t}:\left(1+r_{t+1}\right)=\rho V_{t+1}^{\prime}$

$L_{t}: y_{L t}=w_{t}$

The Benveniste-Scheinkman condition is:

$V_{t}^{\prime}=\left[y_{k_{t}}+\rho\left(1-\delta_{k}\right) V_{t+1}^{\prime}\right]$

Guessing $V(k)$ to be linear in $k$, i.e., $V\left(k_{t}\right)=V_{0}+V_{1} k_{t}$, we have from (A4) and (A6):

$V_{1}=\frac{\rho y_{k_{t}}}{1-\rho\left(1-\delta_{k}\right)}=\rho\left(1+r_{t+1}\right)$

where $y_{L t}$ and $y_{k_{t}}$ are the marginal product of capita with respect to labour and capital, respectively. Moreover, substituting (A7) into the above expression for $V_{k}$, and using (A3) and (A5), we can prove that $V_{0}=0$.

Using (A5) and (A7), we obtain the efficiency conditions given by (8) and (9). Note with the production structure in (7) and $k_{t}=\bar{k}_{t}$ to hold in equilibrium, $y_{L t}=A(1-\alpha) k_{t}\left(L_{t}\right)^{(-\alpha)}$ and $y_{k t}=A \alpha\left(L_{t}\right)^{(1-\alpha)}$.

Following the same steps as above, and replacing $w_{t}$ with $\bar{w}_{t}$ and $\left(1+r_{t+1}\right)$ with $\overline{\left(1+r_{t+1}\right)}$ under the active policy regime, the result will be equations (19) and (20). 